\title{
miR-942 promotes cancer stem cell-like traits in esophageal squamous cell carcinoma through activation of $\mathrm{Wnt} / \boldsymbol{\beta}$-catenin signalling pathway
}

\author{
Chunlei $\mathrm{Ge}^{1, *}$, Shikai Wu ${ }^{2, *}$, Weiwei Wang ${ }^{3, *}$, Zhimin Liu ${ }^{1}$, Jianhua Zhang ${ }^{1}$, Zhenyu \\ Wang ${ }^{4}$, Ruilei Li ${ }^{1}$, Zhiwei Zhang ${ }^{1}$, Zhen Li ${ }^{1}$, Suwei Dong ${ }^{1}$, Ying Wang ${ }^{1}$, Yuanbo \\ Xue ${ }^{1}$, Jinyan Yang ${ }^{1}$, Qinghua Tan ${ }^{1}$, Ziping Wang ${ }^{5}$ and Xin Song ${ }^{1}$ \\ ${ }^{1}$ Department of Cancer Biotherapy Center, The Third Affiliated Hospital of Kunming Medical University (Tumor Hospital of \\ Yunnan Province), Kunming, Yunnan, People's Republic of China \\ ${ }^{2}$ Department of Radiation Oncology, Affiliated Hospital of Academy of Military Medical Sciences, Beijing, People's Republic \\ of China \\ ${ }^{3}$ Department of Thoracic Surgery, The Third Affiliated Hospital of Kunming Medical University (Tumor Hospital of Yunnan \\ Province), Kunming, Yunnan, People's Republic of China \\ ${ }^{4}$ Department of Biomedical Engineering Research Center, Kunming Medical University, Kunming, Yunnan, People's Republic \\ of China \\ ${ }^{5}$ Department of Medical Oncology, Cancer Institute and Hospital, Chinese Academy of Medical Sciences (CAMS), Beijing, \\ People's Republic of China \\ * These authors have contributed equally to this work.
}

Correspondence to: Xin Song, email: songxin68@126.com

Ziping Wang, email: ziping_wang@163.com

Keywords: miR-942, cancer stem cells, Wnt/ß-catenin signalling pathway, esophageal squamous cell carcinoma

Received: December 20, $2014 \quad$ Accepted: March 02, 2015

Published: March 30, 2015

This is an open-access article distributed under the terms of the Creative Commons Attribution License, which permits unrestricted use, distribution, and reproduction in any medium, provided the original author and source are credited.

\section{ABSTRACT}

The Wnt/ $\beta$-catenin signalling pathway is known to play a vital role in the maintenance of cancer stem cells (CSCs), which are reported to be the origine of malignant cancers, and result in poor prognosis of multiple kinds of cancer. Therefore, it is of great importance to illuminate the mechanism by which the Wnt/ $\beta$-catenin pathway regulates the cancer stem cell-like traits in cancers. Here, we report that miR942 is significantly upregulated in esophageal squamous cell carcinoma (ESCC), and miR-942 levels are associated with poor prognosis in ESCC patients. Overexpression of miR-942 promotes, whereas inhibition of miR-942 decreases, the tumor sphere formation, the $\mathrm{CD}^{+} \mathrm{O}^{+}$subpopulation cells and the expression of pluripotency associated markers. Moreover, in vivo assay shows that miR-942 overexpressing cells form larger tumors and display higher tumourigenesis. Furthermore, we demonstrate that miR-942 upregulates the $\mathrm{Wnt} / \beta$-catenin signaling activity via directly targeting SFRP4, GSK3 $\beta$ and TLE1, which are multiple level negative regulators of the Wnt/ $\beta$ catenin signaling cascade. In addition, our results indicate that c-myc directly binds to the miR-942 promoter and promotes its expression. Taken together, our findings establish an oncogenic role of miR-942 in ESCC and indicate that miR-942 might be an effective therapeutic target for ESCC.

\section{INTRODUCTION}

Cancer stem cells (CSCs), a small population of cancer cells that possess the ability to self-renew and differentiate, are generally responsible for cancer initiation and poor prognosis [1-3]. It has been reported that CSCs exhibit both stem cell-like traits and cancer properties. Only a small portion of CSCs, or even a single CSC, can form a tumour [4]. Meanwhile, CSCs exhibit greater resistance to cancer treatment than cancer cells, such as 
chemotherapy and radiotherapy $[5,6]$. Several studies have reported that CSCs play a vital role in esophageal squamous cell carcinoma (ESCC) progression. For example, Forghanifard et al. found that SALL4 and SOX2, which are stemness state transcriptional factors involving in maintenance of pluripotency and self-renewal, played vital role in ESCC progression [7]. Zhao and colleagues have demonstrated the stem cell-like side populations are a source of chemo-resistance and metastasis in esophageal cancer [8]. Therefore, targeting CSCs could be an effective treatment for ESCC therapy. And it is vital to understand the molecular mechanisms of which control CSCs in ESCC.

The Wnt/ $\beta$-catenin signalling pathway, a key molecular pathway controlling the function of stem cells, has been shown to play an important role in CSCs [9-11]. The canonical Wnt/ $\beta$-catenin signaling is stimulated by the secreted Wnt ligands, which bind to the Frizzled (FZD) family receptors and LRP5/LRP6 co-receptor to trigger the $\beta$-catenin signalling cascade. Receptors activation leads to the phosphorylation of Dishevelled (Dvl), and consequently release $\beta$-catenin from the "destruction complex" - Axin, adenomatous polyposis coli (APC), casein kinase $1 \alpha(\mathrm{CK} 1 \alpha)$, and glycogen synthase kinase $3 \beta$ (GSK3 $\beta$ ). Thereby, $\beta$-catenin translocates to the nucleus and binds to the N-terminal of the TCF/LEF transcriptional factor, thus activating downstream target genes [12-14]. The Wnt/ $\beta$-catenin pathway has been shown to be constitutively activated in various types of cancer, leading to cell reprogramming and generation of a stem-like phenotype $[15,16]$. Numerous studies have shown that $\mathrm{Wnt} / \beta$-catenin signalling is hyperactivated in multiple cancers $[12,17]$. In colon cancer, inappropriate permanent activation of the Wnt cascade always due to the loss of APC allele, Axin mutation or activating $\beta$-catenin point mutation $[17,18]$. Tanaka et al. have reported that a novel member of the human frizzled (FzD) gene family FzE3 was expressed only in esophageal cancer tissues, but not in adjacent normal tissues [19].

On the other hand, dysregulation of negative regulators could also contribute to constitutive activation of the $\mathrm{Wnt} / \beta$-catenin signalling in cancer. These negative regulators are involved in three layers in $\mathrm{Wnt} / \beta$-catenin signalling: extracellular secreted Wnt inhibitors, such as the secreted Frizzled-related proteins (sFRPs), which serve as Wnt antagonists and inhibit Wnt binding to Frizzled receptors [20-22]; intracellular canonical Wnt inhibitorsAxin, adenomatous polyposis coli (APC), casein kinase $1 \alpha(\mathrm{CK} 1 \alpha)$, and glycogen synthase kinase $3 \beta$ (GSK3 $\beta$ ), which form the destruction complex and prevent $\beta$-catenin from translocating into the cell nucleus [23]; and nuclear transcriptional suppressors, such as TLE1, NLK and CtBP2, which inhibit the transcriptional activity of LEF/ TCF [24-26]. However, how these negative regulators of the Wnt/ $\beta$-catenin signalling pathway are concomitantly deregulated in cancer is largely unclear.
In the present study, we found that the microRNA miR-942 was markedly overexpressed in ESCC and promoted the stem cell-like traits by inhibition of three negative regulators of $\mathrm{Wnt} / \beta$-catenin pathway, including sFRP4, GSK3 $\beta$ and TLE1. Therefore, our results suggest that miR-942 might be a potential therapeutic target for ESCC.

\section{RESULTS}

\section{miR-942 overexpression correlates with ESCC progression}

By analysis the Cancer Genome Atlas (TCGA) microarray data set consisting of 177 primary esophageal cancer tissues and 13 normal esophageal tissues, miR-942 was significantly upregulated in tumour tissues compared to normal tissues (Fig. 1A and Supplementary Fig. 1). Furthermore, real-time PCR analysis showed that miR942 was ubiquitously overexpressed in 10 ESCC samples compared with the paired normal tissues and in all 12 ESCC cell lines compared with 2 NEECs (Fig. 1B and 1C). Collectively, these findings suggested that miR-942 expression is significantly increased in ESCC.

The observed upregulation of miR-942 prompted us to further investigate the clinical relevance of miR942 in ESCC progression. We therefore examined miR942 expression in a cohort of 158 archived human ESCC specimens (Supplementary Table 1). Statistical analysis revealed that miR-942 expression was positively correlated with clinical stage $(P<0.001)$, tumour-node-metastasis (TNM) classification (T: $P=0.005 ; \mathrm{N}: P<0.001 ; \mathrm{M}: P$ $=0.004)$, and histologic differentiation $(P=0.045)$ in patients with ESCC (Fig. 1D and Supplementary Table 2). Importantly, patients with higher miR-942 expression had a shorter survival time, whereas patients with lower miR-942 expression had a longer survival time $(P=0.01$; Fig. 1E). Moreover, Univariate and multivariate analyses indicated that miR-942 expression and clinical stage were independent prognostic factors in ESCC (Supplementary Table 3). Taken together, these results indicate a possible link between miR-942 overexpression and human ESCC progression.

\section{Upregulation of miR-942 promotes cancer stem cell-like traits in ESCC}

In attempt to understand the biological effect of miR-942 in ESCC progression, miR-942 was stably transduced into the Eca109 and Kyse510 ESCC cell lines to generate Eca109/miR-942 and Kyse510/miR942 cell lines (Supplementary Fig. 2A). A tumour sphere formation assay showed that miR-942-transduced cells formed more and larger spheres than vector-tranduced 
A

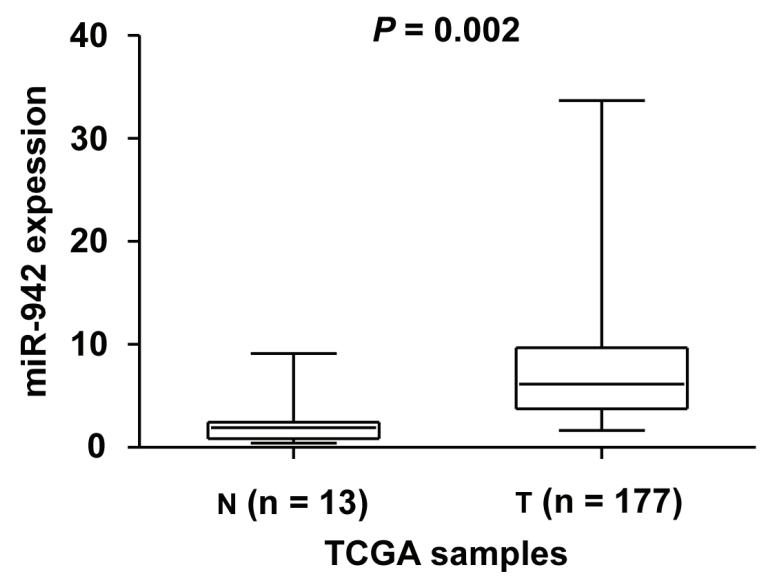

C

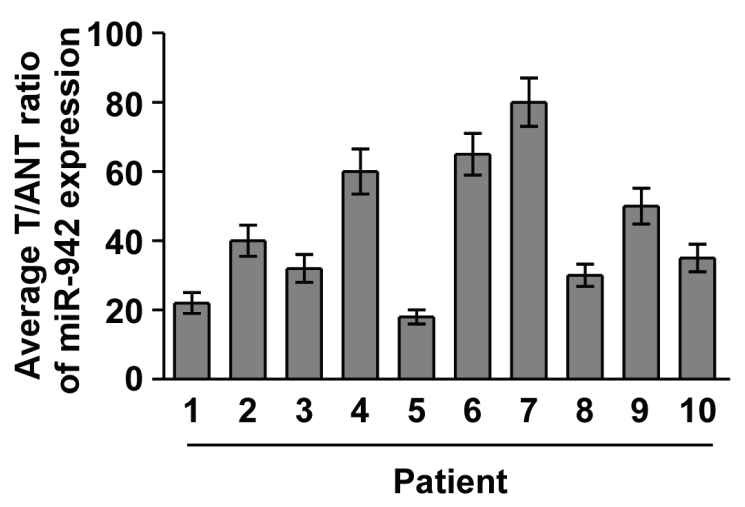

E

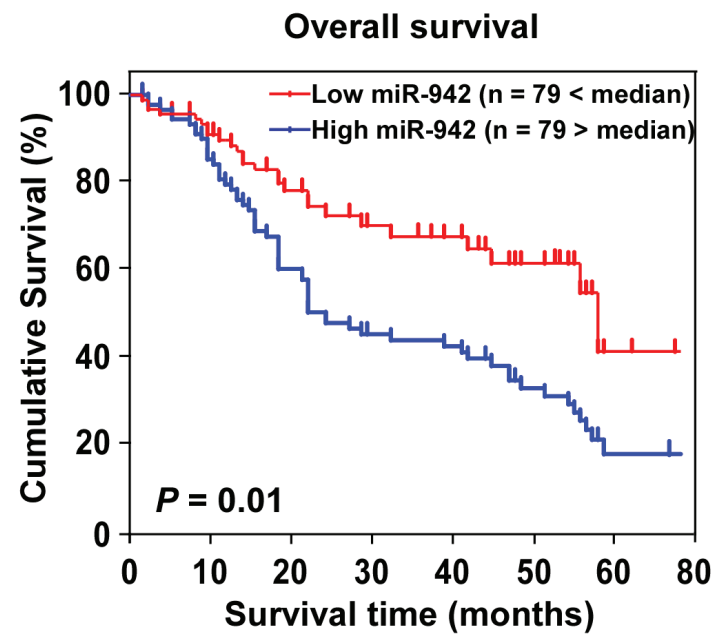

B

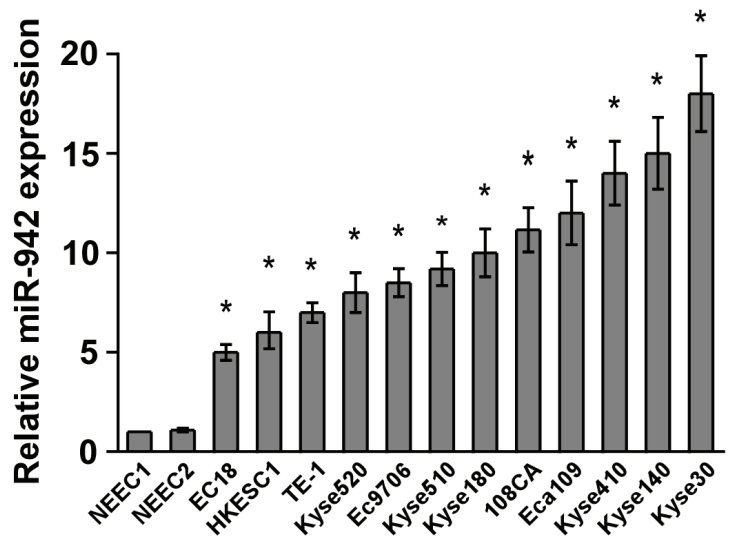

D

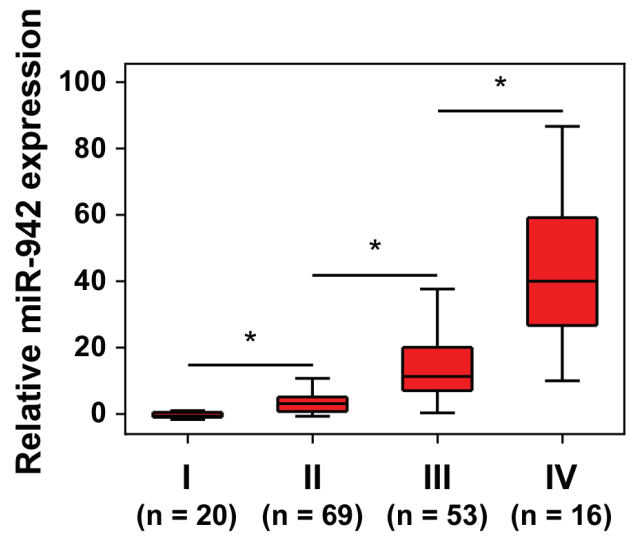

Clinical stage

Figure 1: Overexpression of miR-942 is positively associated with ESCC prognosis. (A) Expression profiling of miR-942 from the Cancer Genome Atlas (TCGA) datasets in primary esophageal tumours (T, $\mathrm{n}=177$ ) and the adjacent normal tissues (ANT, $\mathrm{n}=13$ ) ( $P=0.002$ ). (B-C) Real-time PCR analysis of miR-942 expression in 2 NEECs and 12 ESCC cell lines (B), as well as 10 paired ESCC samples (T) and adjacent normal tissues (ANT). Transcript levels were normalized by to U6 expression. Each bar represents the mean \pm SD of three independent experiments. ${ }^{*} P<0.05$. (D) Correlation of miR-942 expression in WHO grading of ESCC assessed by real-time PCR. Transcript levels were normalized by $U 6$ expression. The boundaries of the boxes represent the lower and upper quartiles; lines within boxes and whiskers denote median and extremum, respectively. ${ }^{*} P<0.05$ (E) Kaplan-Meier curves of ESCC patients with low- versus high-expression of miR-942 ( $n=158 ; P<0.001, \log$-rank test). 
cells (Fig. 2A and 2B). Additionally, CD90 positive cells, which were well-known esophageal CSC marker, were dramatically increased in miR-942-transduced cells compared with vector-tranduced cells (Fig. 2C). Furthermore, miR-942 overexpression significantly upregulated the mRNA expression levels of multiple pluripotency factors, including ABCG2, KLF4, SOX2, OCT4, and NANOG (Fig. 2D). However, the proliferative rate of miR-942-transduced Eca109 and Kyse510 cells is only slightly quick compare to the vector control cells (Fig. 2E). Collectively, our results suggest that miR-942 overexpression promotes the stem cell-like traits of ESCC cells.

\section{miR-942 inhibition suppresses ESCC stem cell-} like traits

To examine the role of endogenous miR-942 in ESCC stem cell -like traits, antagomir-942, an antisense-based specific inhibitor against miR-942, was applied as antagonists to silence endogenous miR-942 (Supplementary Fig. 2B). As shown in Fig. 3A and 3B, the tumour sphere formation assay revealed that when
A

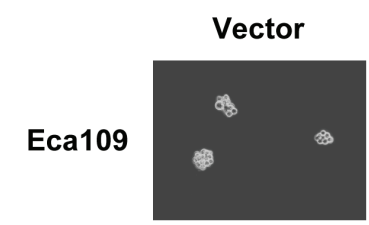

miR-942

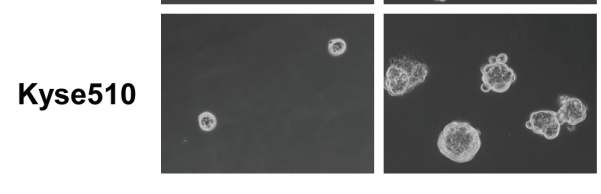

C
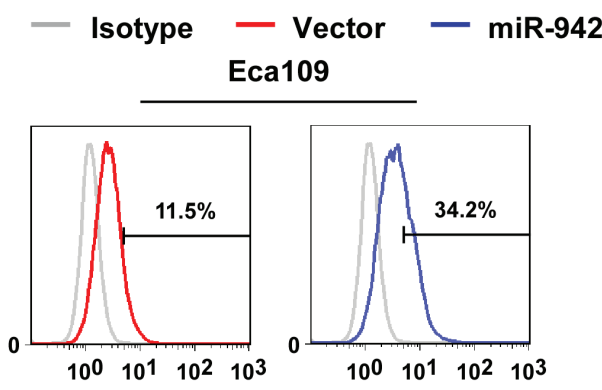

B

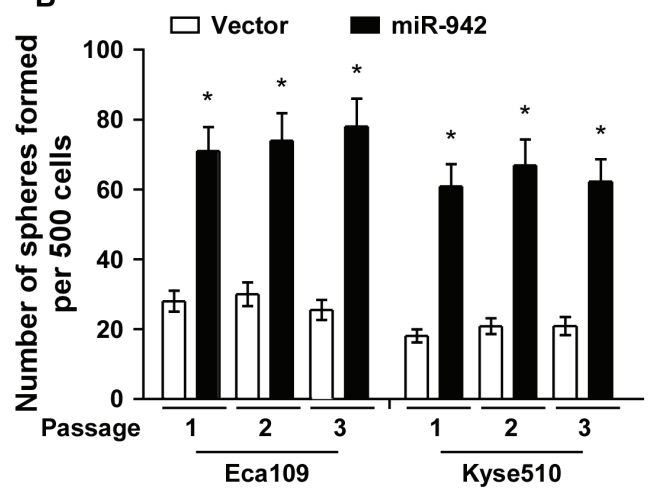

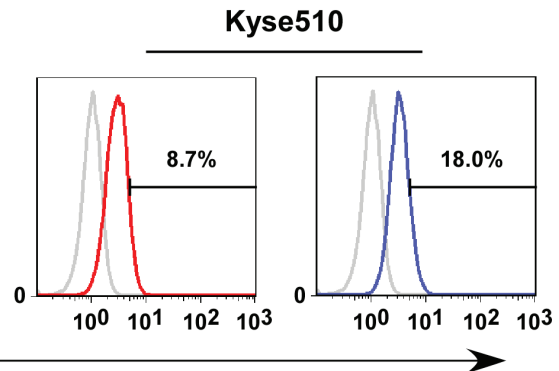

CD90

D
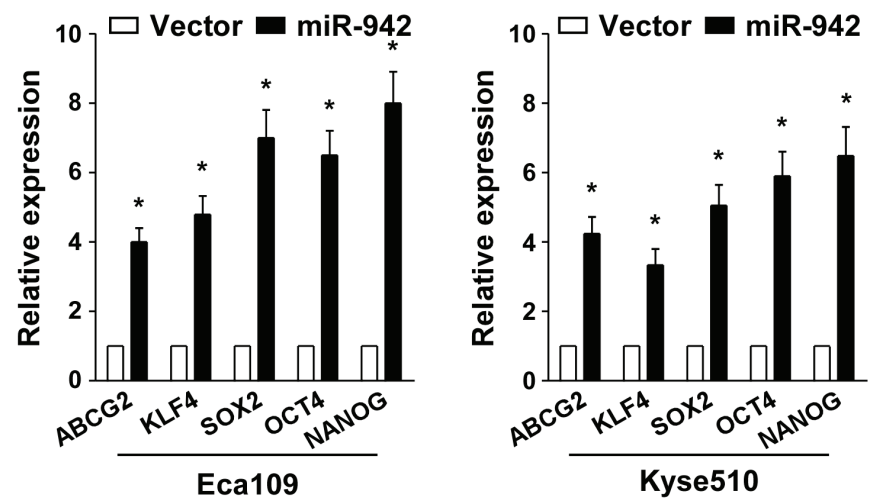

E

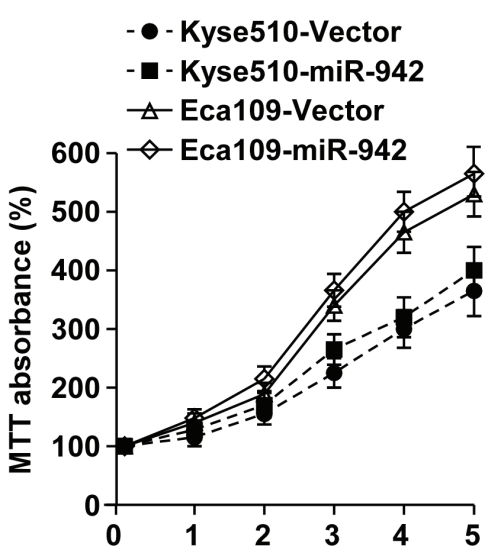

Figure 2: miR-942 overexpression promotes cancer stem-like traits in ESCC. (A-B) Representative micrographs (left) and quantification (right) of tumourspheres formation in miR-942-overexpression or vector cells. Scale bar, $100 \mu \mathrm{m}$. (C) Effects of miR-942overexpression cells on the distribution of CD $90^{+}$cells using flow cytometric analysis. $* P<0.05$ (D) Real-time PCR analysis of the mRNA expression of pluripotency-associated markers in the indicated cells. Transcript levels were normalized to GAPDH expression. Error bars represent mean \pm SD from three independent experiments. ${ }^{*} P<0.05$ (E) MTT assay revealed that miR-942 overexpression is only slightly quick in Eca109 and Kyse510 stable cell lines compare to the vector control cells at indicated times after seeding. 
miR-942 was inhibited, the cells formed fewer and smaller spheres. Similarly, CD90 population was dramatically decreased in antagomir-942 cells compared with control cells (Fig. 3C). Furthermore, miR-942 inhibition significantly decreased the mRNA expreesion of ABCG2, KLF4, SOX2, OCT4, and NANOG (Fig. 3D). However, inhibition of miR-942 is only slightly suppressed in Eca109 and Kyse510 compare to the control cells (Fig. $3 \mathrm{E})$. Thus, our experiments indicated that endogenous miR-942 might act as a cancer stem cell inducer which

A

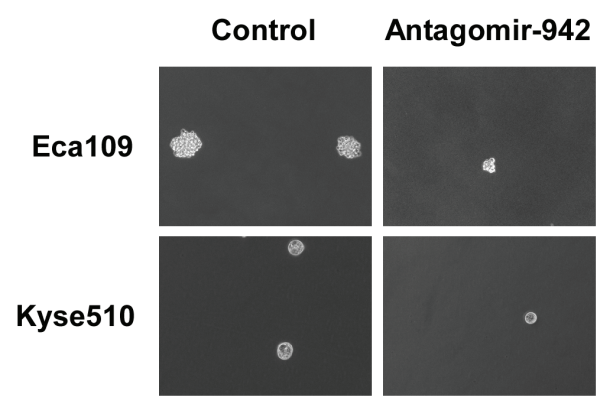

C

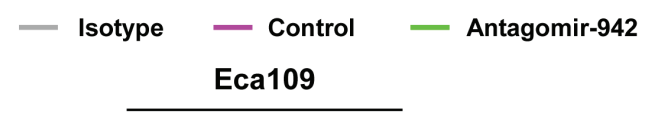

promotes ESCC stem cell-like traits

\section{Upregulation of miR-942 promotes tumourigenecity of ESCC cells in vivo}

The biological effect of miR-942 on ESCC progression was further examined using an in vivo tumour model. Eca109/miR-942 or Eca109/vector cells were subcutaneously xenografted into the NOD/SCID mice. As shown in Fig. 4A-D, the tumours formed by Eca109/

B

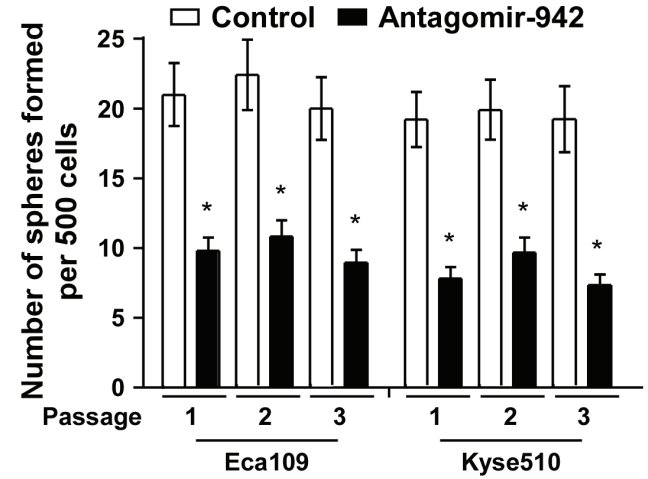

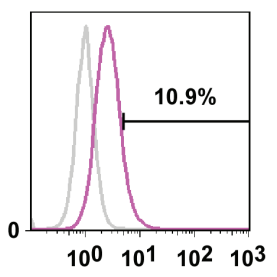
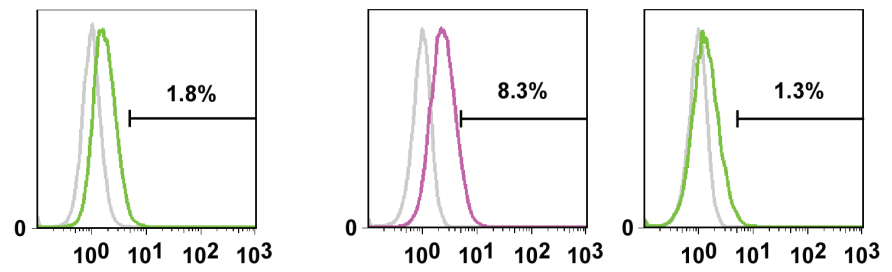

CD90

D

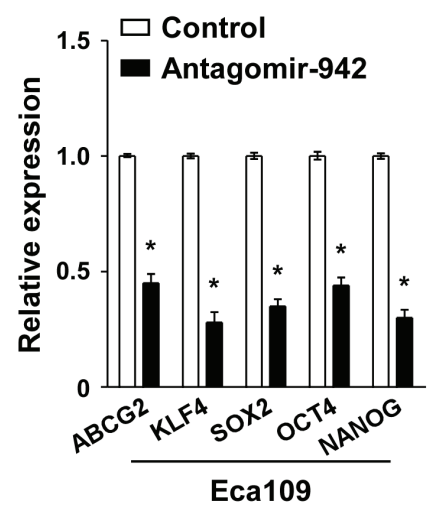

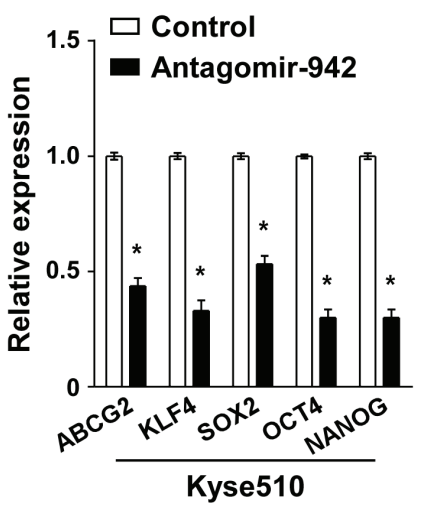

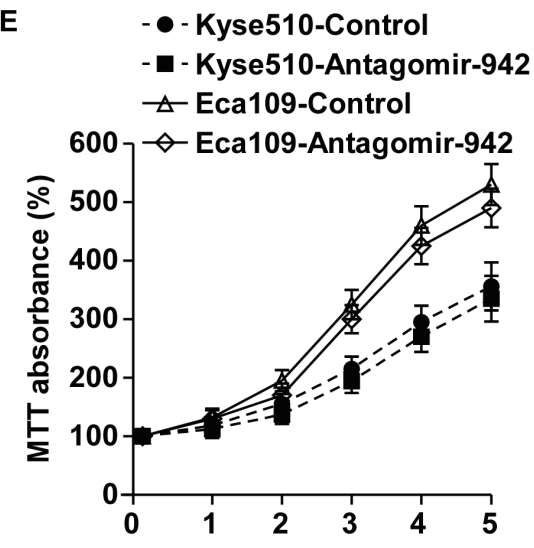

Figure 3: miR-942 inhibition reduces stem cell-like traits in ESCC. (A-B) Representative micrographs (left) and quantification (right) of tumourspheres formation in antagomir-942 or control cells. Scale bar, $100 \mu \mathrm{m}$. (C) Effects of antagomir-942 or control cells on the distribution of $\mathrm{CD} 0^{+}$cells using flow cytometric analysis. ${ }^{*} P<0.05$ (D) Real-time PCR analysis of the mRNA expression of pluripotency-associated markers in antagomir-942 or control cells. Transcript levels were normalized to GAPDH expression. Error bars represent mean $\pm \mathrm{SD}$ from three independent experiments. ${ }^{*} P<0.05$. (E) MTT assay revealed that inhibition of miR-942 is only slightly suppressed in Eca109 and Kyse510 compare to the control cells at indicated times after seeding. 
Table 1: Effect of miR-942 on the ability of ESCC cells to form tumours in vivo.

\begin{tabular}{|c|c|c|c|}
\hline \multirow{2}{*}{ Cell type } & \multicolumn{3}{|c|}{ Number of cells inoculated } \\
\cline { 2 - 4 } & $\mathbf{1 \times \mathbf { 1 0 } ^ { 4 }}$ & $\mathbf{1} \times \mathbf{1 0}^{\mathbf{3}}$ & $\mathbf{1}^{*} \times \mathbf{1 0}^{\mathbf{2}}$ \\
\hline Eca109-vector & $6 / 6$ & $3 / 6$ & $0 / 6$ \\
\hline Eca109-miR-942 & $6 / 6$ & $6 / 6$ & $5 / 6$ \\
\hline Eca109-NC & $6 / 6$ & $3 / 6$ & $0 / 6$ \\
\hline Eca109-Antagomir-942 & $2 / 6$ & $0 / 6$ & $0 / 6$ \\
\hline
\end{tabular}

A

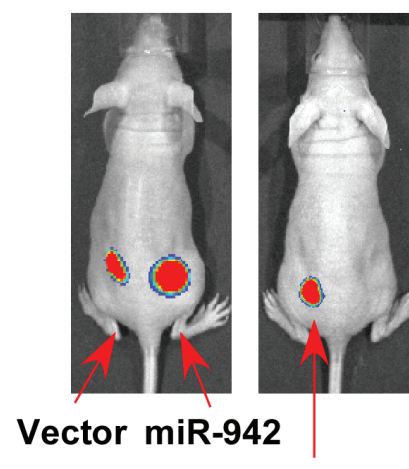

Control

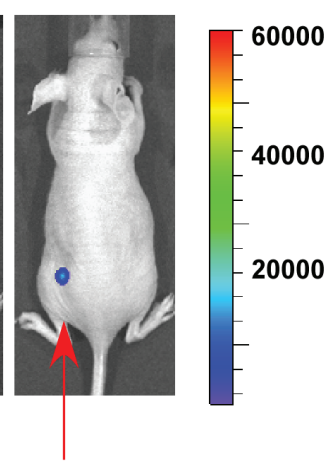

Antago-

mir-942

B

C

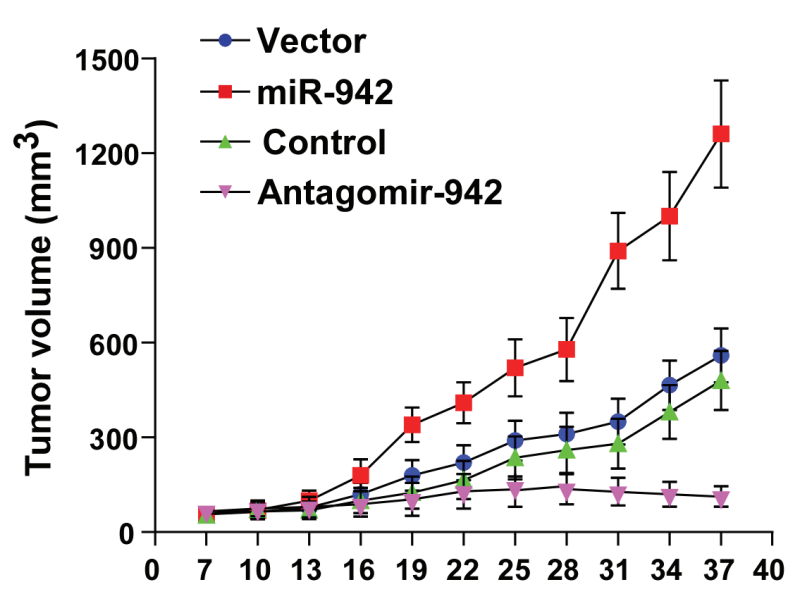

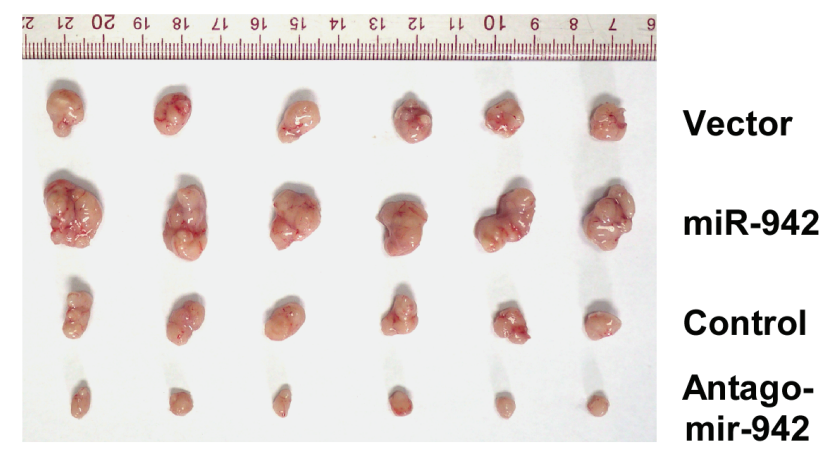

D

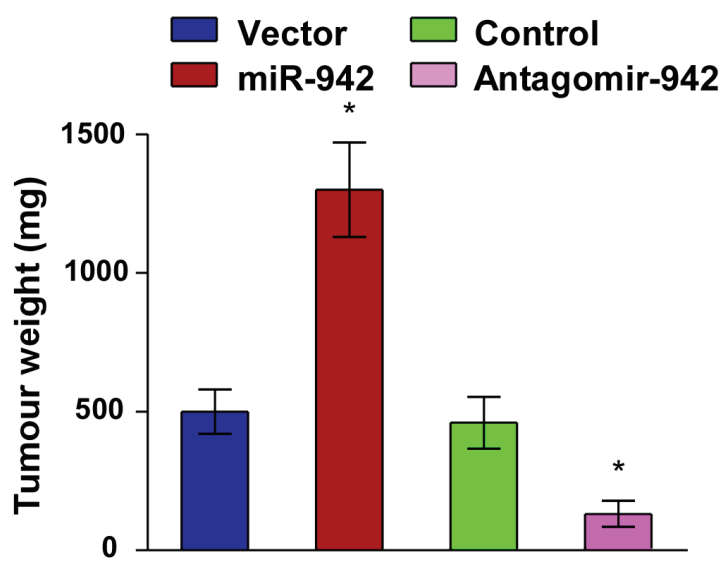

Figure 4: Upregulation of miR-942 increases tumourigenesis of ESCC cells in vivo. Xenograft model in nude mice. (A) Representative images of tumour-bearing mice. (B) Images of the tumours from each group. (C) Tumour volumes were measured on the indicated days. (D) Mean tumour weights. Each bar represents the mean $\pm \mathrm{SD}$ of three independent experiments. ${ }^{*} P<0.05$. 
miR-942 cells were larger, in both size and weight, than the tumours formed from vector control cells. In contrast, when endogenous expression of miR-942 was inhibited using antagomir-942, the tumours were obviously smaller and lighter than those formed by control cells. The tumours formed by Eca109/miR-942 cells were significantly larger than the vector control tumours, when $1 \times 10^{4}$ or $1 \times 10^{3}$ cells mixed with matrigel were subcutaneously inoculated into the mice. Importantly, only Eca109/miR-942 cells formed tumours when $1 \times 10^{2}$ cells were implanted (Table 1). These results indicated that miR-942 strongly promotes ESCC tumourigenesis in vivo.

\section{miR-942 directly targets sFRP4, GSK3ß, and TLE1}

As Wnt/ $\beta$-catenin signalling pathways is the major molecular pathway controlling CSCs and promotes tumour progression [27], we hypothesis miR-942 might regulate Wnt/ $\beta$-catenin signalling. As expected, miR942 overexpression markedly increased the luciferase activity of the TOP flash/ FOP flash reporter. Conversely, transfection of antagomir-942 reduced the luciferase activity, and mutant miR-942 had no effect (Fig. 5A), indicating that miR-942 activates Wnt/ $\beta$-catenin signalling. Using publicly available algorithms (TargetScan6.2 and miRanda), we found that sFRP4, GSK3 $\beta$, and TLE1, the multiple negative regulators of $\mathrm{Wnt} / \beta$-catenin pathway, might be the potential targets of miR-942 (Fig. 5B). Western blot analysis revealed that the expressions of sFRP4, GSK3 $\beta$, and TLE1 was drastically decreased in miR-942-transduced cells but pronouncedly elevated in antagomir-942 cells, compared with their corresponding control cells (Fig. 5C). In addition, results of the luciferase reporter activities, which linked to the 3'UTRs of sFRP4, GSK3 $\beta$, and TLE1, indicated that miR-942 overexpression significantly repressed, whereas inhibition of endogenous miR-942 increased, the luciferase activity of 3'UTRs, and ectopically expressing mutant miR-942 had no inhibitory effect on the 3'UTRs luciferase activity (Fig. 5D). Importantly, results of the miRNP immunoprecipitation assay showed that miR-942 selectively associated with sFRP4, GSK3 $\beta$, and TLE1, but not GAPDH or 5s rRNA (Fig. 5E). Hence, our results indicate that sFRP4, GSK3 $\beta$, and TLE1 are the bona fide targets of miR-942.

\section{miR-942 maintains cancer stemness via activating Wnt/ $\beta$-catenin signalling pathway}

Since sFRP4, GSK3 $\beta$, and TLE1 are important negative regulators of the $\mathrm{Wnt} / \beta$-catenin pathway, we then examined the effect of miR-942 on the Wnt/ $\beta$ catenin pathway. Western blot analysis proved that miR942 overexpression induced, wheras miR-942 inhibition decreased, the nuclear accumulation of $\beta$-catenin (Fig. 5C).
To explore the functional significance of sFRP4, GSK3 $\beta$, and TLE1 in stem cell-like traits and $\beta$-catenin activation induced by miR-942, we silenced the endogenous SFRP4, GSK3 $\beta$, and TLE1 using siRNAs in antagomir-942 cells (Supplementary Fig. 3). As shown in Fig. 5F and 5G, individually silencing sFRP4, GSK3 $\beta$, or TLE1 increased the tumour sphere formation and enhanced the TOP flash/ FOP flash activity of antagomir-942 cells. These results demonstated that sFRP4, GSK3 $\beta$, and TLE1 are important for miR-942-induced stem cell-like traits and indicated that $\mathrm{Wnt} / \beta$-catenin signalling is a functional mediator for miR-942-induced function in ESCC cell lines.

\section{miR-942 is upregulated by c-myc and clinically correlated with $\mathrm{c}-\mathrm{myc}$ and $\beta$-catenin}

To determine the mechanism of miR-942 upregulation in ESCC, the miR-942 promoter region was analysed using the UCSC genome browser (http:// genome.ucsc.edu/), and two binding sites for c-myc (E-box1 and E-box2) were predicted on the promoter of miR-942 (Fig. 6A). Real-time PCR indicated that miR-942 was upregulated in c-myc-elevated cells and was downregulated in c-myc-silenced cells (Fig. 6B). Furthermore, a dual-luciferase reporter assay showed that c-myc obviously activates miR-942 through binding to the first E-box (E-box1) (Fig. 6B). Meanwhile, when mutated the second E-box, no obvious alterations were observed. Moreover, chromatin immunoprecipitation (CHIP) assays showed high binding affinity of endogenous c-myc with the first E-box region (Fig. 6C). Collectively, our results indicated that c-myc directly binds to the promoter of miR942 and promotes its expression. Finally, using 10 freshly collected clinical ESCC samples, miR-942 expression was shown to be positively correlated with c-myc $(\mathrm{r}=0.723$, $P=0.01)$, nuclear $\beta$-catenin expression $(\mathrm{r}=0.774, P=$ 0.03 ) (Fig. 6D and 6E), further supporting the notion that miR-942 is upregulated by c-myc and promoted stem-cell like traits by activating Wnt/ $\beta$-catenin signalling in ESCC.

\section{DISCUSSION}

To our knowledge, the present study is the first time to show the central role of miR-942 in promoting ESCC tumourigenesis. Using microRNA screening and realtime PCR assays, we found that miR-942 was strongly overexpressed in ESCC and was positively correlated with poor prognosis in this cancer. Further, miR-942 induced ESCC stem-like traits through directly targeting sFRP4, GSK3 $\beta$ and TLE1, which are important negative regulators of the $\mathrm{Wnt} / \beta$-catenin pathway. Moreover, c-myc was found to directly bind to miR-942 promoter and upregulates miR-942 expression. Taken together, our results revealed a novel mechanism by which miR-942 regulates ESCC stem cell-like traits through activating the 
A

$\square$ Vector

miR-942

Control

Antagomir-942 sFRP4-3'UTR 5' 545UUUUUGAAAAAUCUAGAGAAGU566 3'

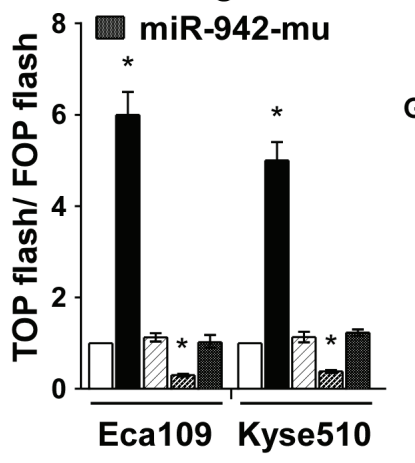

D

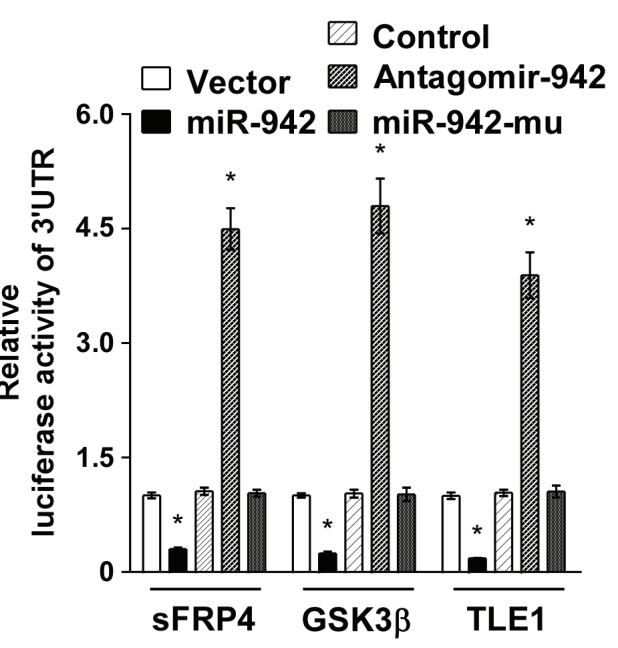

F

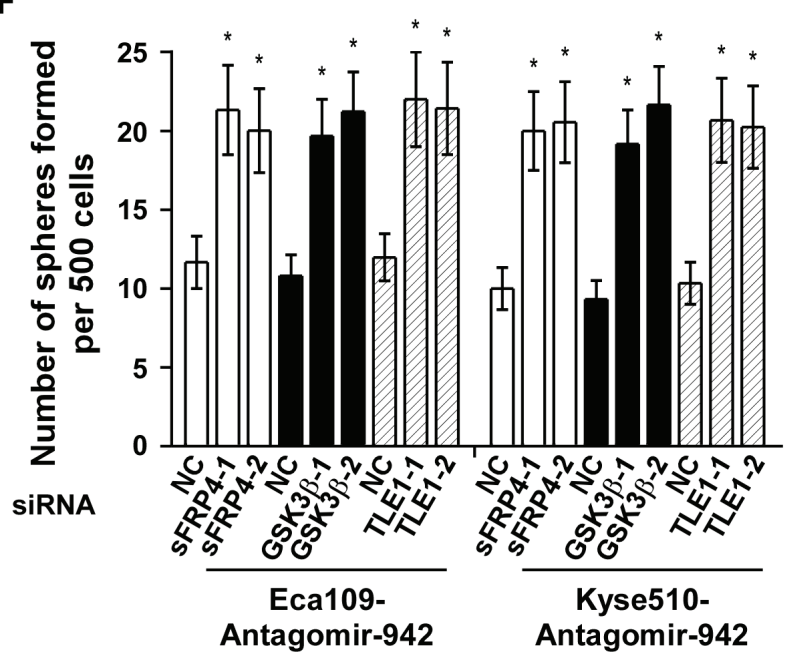

G
B

C
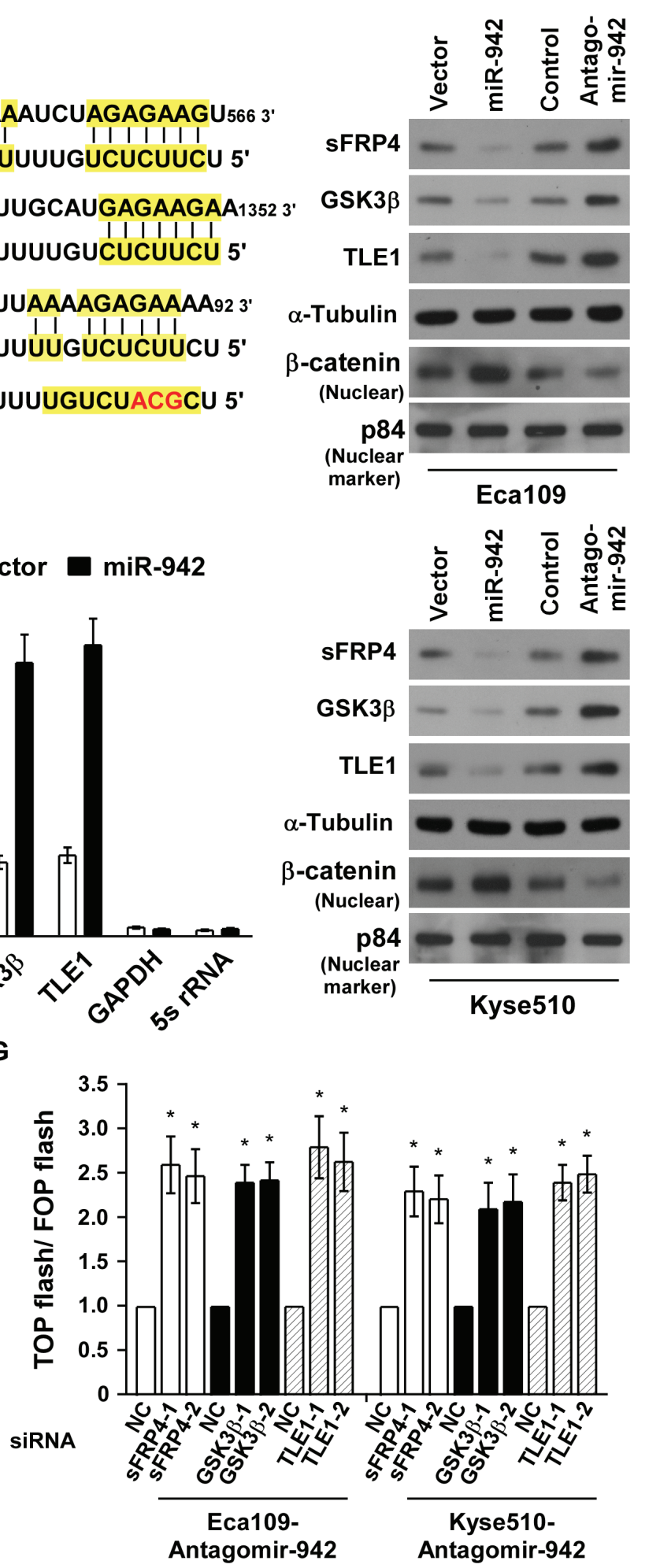

Figure 5: miR-942 directly targets SFRP4, GSK3ß, and TLE1. (A) Indicated cells transfected with TOP flash/FOP flash and Renilla pRL-TK plasmids were subjected to dual-luciferase assays 48 hours after transfection. Reporter activity detected was normalized by Renilla luciferase activity. (B) Predicted miR-942 target sequences in the 3'-UTRs of sFRP4, GSK3 $\beta$ and TLE1 and mutant containing three altered nucleotides in the seed sequence of miR-942 (miR-942-mu). (C) Western blotting analysis of sFRP4, GSK3 3, TLE1 and nuclear $\beta$-catenin in the indicated cells. $\alpha$-Tubulin served as the loading control. (D) Luciferase activity of targets 3'UTR in the indicated cells. (E) miRNP immunoprecipitation assay showed associations of miR-942 with sFRP4, GSK3 $\beta$ and TLE1. GAPDH and 5s rRNA served as a negative control. (F) Quantification of indicated tumoursphere cells with specific siRNA transfection. (G) Luciferase activity of TOP flash/ FOP flash in the indicated cells. Each bar represents the mean \pm SD of three independent experiments. ${ }^{*} P<0.05$. 
Wnt/ $\beta$-catenin pathway, suggesting that miR-942 might function as a therapeutic target for ESCC.

Esophageal cancer is one of the most aggressive cancers which ranks as the sixth cause of cancer-related deaths worldwide [28]. Esophageal squamous cell carcinoma (ESCC) occuring in the middle or upper third of the esophageal, and adenocarcinoma (EAC) occuring in the distant third or oesophgogastric junction, are the two major histologic subtypes of esophageal cancer. ESCC leads to significant morbidity and mortality in developing countries, such as China and Iran, where approximately $90 \%$ of all cases of esophageal cancer are ESCC [29]. Surgical resection combines with neoadjuvant chemoor radio-therapy, are the common therapeutic methods used nowadays. However, despite advances in medical diagnosis and treatment, the prognosis of ESCC has not significantly improved, and the 5-year survival rate for ESCC patients ranges only between $15 \%$ and $40 \%$.
A
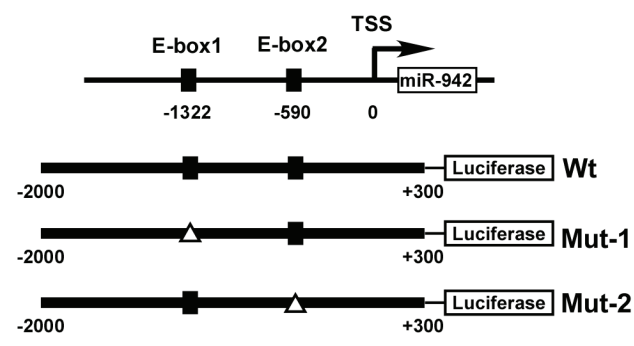

C

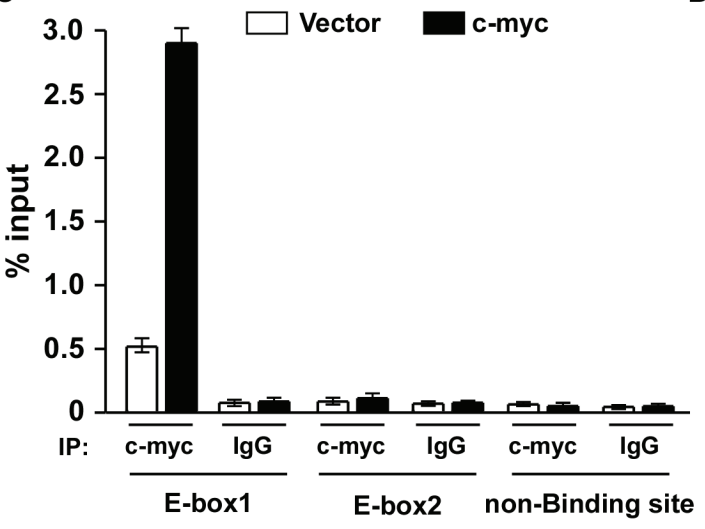

B

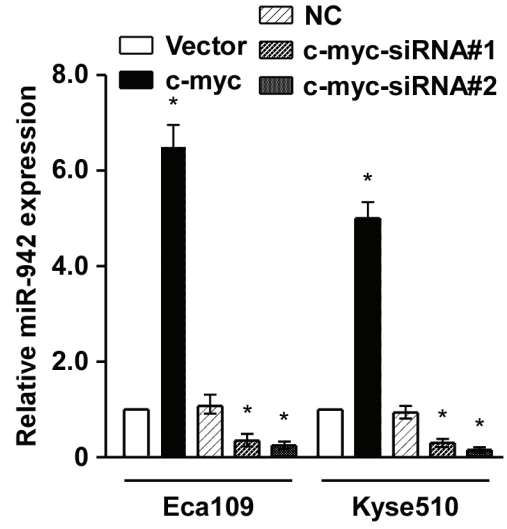

D

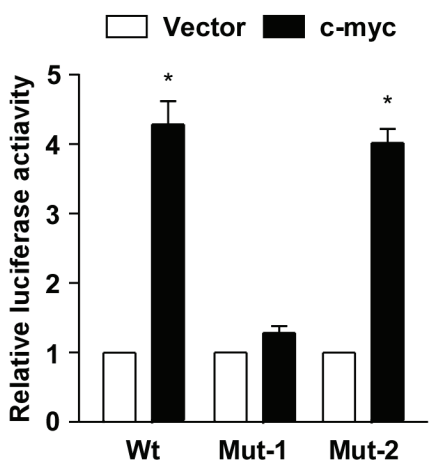

$\begin{array}{llllllllll}\text { T1 } & \text { T2 } & \text { T3 } & \text { T4 } & \text { T5 } & \text { T6 } & \text { T7 } & \text { T8 } & \text { T9 } & \text { T10 }\end{array}$
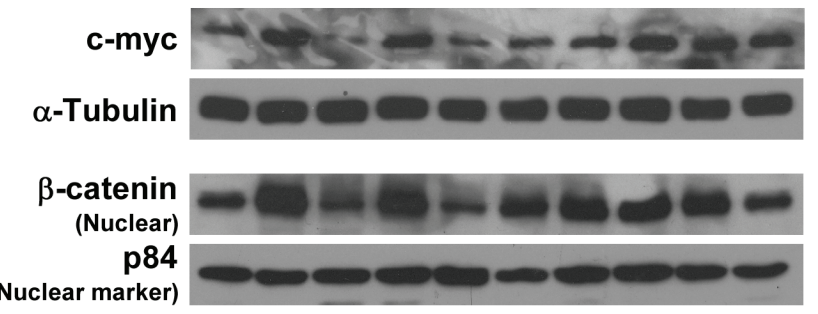

E
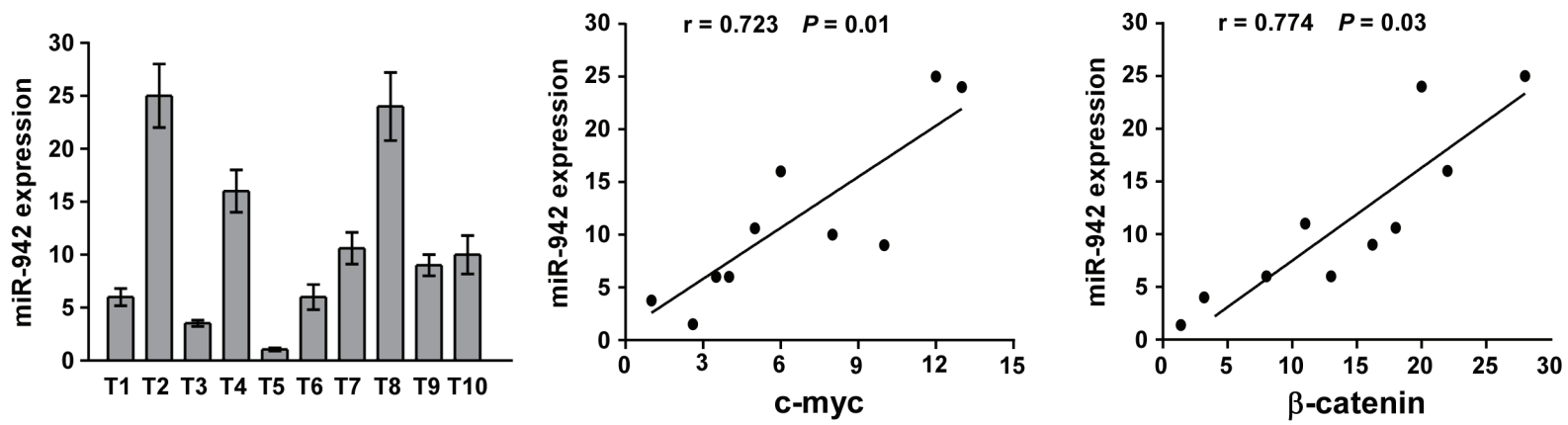

Figure 6: miR-942 is upregulated by c-myc and clinically corelated with c-myc and $\boldsymbol{\beta}$-catenin. (A) Upper: the exact binding sites of c-myc on the human miR-942 promoter. Down: schematic illustration of the cloned fragments of the human miR-942 promoter. E-box 1 and E-box2 were mutated to identify which site is essential for c-myc regulation. (B) Real-time PCR analysis of miR-942 expression in the cells transfected with c-myc or c-myc siRNA. Transcript levels were normalized by U6 expression. c-myc affects the transactivity of miR-942 promoter with or without E-boxes. (C) ChIP-qPCR analyses for the fold enrichment of c-myc at the different promoter regions of human miR-942 in Eca109 cells. (D) Analysis of expression of miR-942 with the expression levels of c-myc and nuclear $\beta$-catenin in 10 freshly collected human ESCC samples. The ratio of fifth sample (c-myc / $\alpha$-tubulin, beta-catenin / $\alpha$-tubulin) was considered as 1.0 . Each bar represents the mean $\pm \mathrm{SD}$ of three independent experiments. 
The most important reason results in poor prognosis of ESCC always due to delayed diagnosis, metastasis, highly relapse rate and a limited understanding of the cellular and molecular mechanisms underlying the initiation, promotion, and progression of ESCC. Nowadays, multiple researchers have proved that the existence of CSCs could lead to therapeautic failure of ESCC [30]. Therefore, targeting CSCs might develop be an effective strategy for cancer therapy, and it is important to explore the properities of CSCs [31, 32].

The Wnt/ $\beta$-catenin signalling pathway is a wellknown pathway involved in regulating self-renewal and oncogenesis in many systems $[33,34]$. In normal physiological state, the $\mathrm{Wnt} / \beta$-catenin signalling pathway regulates downstream genes involved in basic cellular processes, such as cell proliferation, differentiation, migration and cell death $[35,36]$. It means that the Wnt/ $\beta$-catenin signalling should be kept in a normal level to exert normal physiological function. However, extensive findings have shown that the $\mathrm{Wnt} / \beta$-catenin pathway is constitutively activated in many cancers [37]. Understanding the underlying mechanisms is important in for cancer therapy. In the present study, we found miR942 activates $\mathrm{Wnt} / \beta$-catenin pathway in different layers through directly downregulation of sFRP4, GSK3 $\beta$, and TLE1. Therefore, our results uncover a novel mechanism in which $\mathrm{Wnt} / \beta$-catenin pathway constitutively activates in cancer.

sFRP4 is hommologous to the extracellular cysteinerich domain of frizzled, which is a putative Wnt-binding receptor [38]. Through interaction and inhibition of Wnt ligand, sFRP4 exert antagonistic activity in $\mathrm{Wnt} / \beta$-catenin pathway, suggesting that sFRP4 might be a tumour suppressor [39]. Consistently, sFRP4 has been found to be downregulated in several human cancers. Carmon et al. reported that sFRP4 was significantly decreased in endometrial cancer cells and inhibited cell growth [20]. Meanwhile, sFRP4 increases chemotherapeutic sensitivity in glioma stem-like cells and induces apoptosis via inhibiting $W n t / \beta$-catenin signalling [40]. It has been reported that the protein expression of sFRP4 was downregulated through promoter $\mathrm{CpG}$ island methylation in colorectal cancer, mesothelioma, cervical cancer and leukemia [41-44]. However, Zinovyeva and his colleagues showed that the mRNA expression of sFRP4 was higher in ESCC than in normal cells [45], the molecular mechanism underlying sFRP4 protein downregulation in ESCC remained largely unclear. In the current study, we demonstrated first time that miR-942 directly targets the sFRP4-3'UTR, thereby inhibiting sFRP4 protein expression.

In summary, our studies demonstrated that overexpression of miR-942 prmotes stem cell-like traits and tumourigenesis in ESCC by directly suppressing sFRP4, GSK3 $\beta$, and TLE1, which are multiple negative regulators of $\mathrm{Wnt} / \beta$-catenin signalling. Our findings reveal a novel molecular mechanism to explain how constitutive activation of the $\mathrm{Wnt} / \beta$-catenin pathway is maintained in cancers and suggests that miR-942 might serve as a potential therapeutic target for ESCC.

\section{MATERIALS AND METHODS}

\section{Cells}

Primary cultures of normal esophageal epithelial cells (NEECs) were established from fresh specimens of the adjacent noncancerous esophageal tissue taken from an area over $5 \mathrm{~cm}$ from the cancerous tissue, according to previous report [46]. The esophageal cancer cell lines, including Kyse140, Kyse180, Kyse30, Kyse410, Kyse510, Kyse520, Eca109, TE-1, EC18, EC9706, HKESC1 and $108 \mathrm{CA}$ were grown in the DMEM medium (Invitrogen, Carlsbad, CA) supplemented with 10\% fetal bovine serum (HyClone, Logan, UT).

\section{Patient information and tissue specimens}

A total of 158 paraffin-embedded and archived ESCC samples, which were histopathologically and clinically diagnosed at the Department of Pathology, Affiliated Hospital of Academy of Military Medical Science from 2001 to 2006, were examined in this study. Prior patient consent and approval from the Institutional Research Ethics Committee were obtained for the use of these clinical materials for research purposes. Clinical information on the samples is summarized in Supplementary Table 1. Clinical pathological tumournode-metastasis (TNM) staging was determined by the extent of tumour invasion in the esophageal wall and lymphatic and venous invasion status according to the criteria proposed by Union for International Cancer Control (UICC) criteria. Ten freshly collected ESCC tissues and the matched adjacent noncancerous esophageal tissues were frozen and stored in liquid nitrogen until further use.

\section{Primers and oligonucleotides}

Cloning miR-942: 5'- GCCAGATCT TGATTGACTTACAGCCCAGTT-3, and 5'-GCCGAA TTCCACCTGTCTTTATTCCACCC-3'; Cloning c-myc ORF: 5'- GCCAGATCTC TGGATTTT TTTCGGGTAGT-3' and 5'-GCCGAATTCTTACGCACAAG

AGTTCCGTA-3'; Cloning sFRP4 - 3'UTR-luci: 5'-GCCCCGCGGCTTGCCCTAACAACTCA-3' and 5'-GCCCTGCAGTTTCCT TTGGGCGTTG-3'; Cloning GSK3 $\beta$-3'UTR-luci: 
5'-GCCCCGCGGATGTTTGCCGTGAGG A-3' and 5'-GCCCTGCAGCCTGGGTCCACATATTTAC-3';

Cloning TLE1-3'UTR-luci: 5'-G CCCCGCGGCGTTTATAGTTGAATTGG-3' and 5'-GCCCTGCAGTTATTGGTACTAAAGCC T-3'. For depletion of sFRP4, GSK3 $\beta$, TLE1 and c-myc siRNA was synthesized and purified by RIBOBIO Company (Guangzhou, China).

\section{RNA extraction and real-time quantitative PCR (qRT-PCR)}

Total cellular RNA was extracted using the TRIzol solution (Invitrogen), according to the manufacturer's protocol. Complementary DNAs were synthesized and Real-time PCR was performed using RT Real-Time ${ }^{\mathrm{TM}}$ SYBR Green (Bio-Rad Laboratories, Berkeley, CA). The following primers were used: $A B C G 2$ forward: 5'-TGGTGTTTCCTTGTGACACTG-3'; $A B C G 2$ reverse: 5'- TGAGCCTTTGGTTAAGACCG-3'; KLF4 forward: 5'-GTCA GTTCA TCTGAGCG GG-3'; KLF4 reverse: 5'-AGAGTTCCCATCTCAAGGCA-3'; SOX2 forward: 5'-GCTTAGCCTC GTCGATGAAC-3'; SOX2 reverse: 5'-AACCCCAAGATGCACAACTC-3'; OCT4 forward: 5'-G GTTCTCGATACTGGTTCGC-3'; OCT4 reverse: 5'-GTGGAGGAAGCTGACAACAA-3; NANOG forward: 5'-ATGGAGGAGGGAAGAGGAGA-3'; $\quad$ NANOG reverse: 5'- GATTTGTGG GCCTGAAGAAA -3'; $s F R P 4$ forward: 5'-GTTCCTGCAGCCTCTCTTCC-3'; sFRP4 reverse: 5'-GTGTTACGAGTGGCGTTCAA-3'; GSK3 $\beta$ forward: 5'-ACTTCTTGTGGCCTGTCTGG-3' GSK3 $\beta$ reverse: 5'-AGCTTTTGGCAGCATGAAAG-3'; TLE1 forward: 5'-TCAATCTCTTGGC GATTTCA-3' reverse: 5'-AAGACAGAAATGCAGAGGCA-3'; $\quad$ GAPDH forward: 5'-AATGAA GGGG TCATTGATGG-3'; GAPDH reverse: 5'-AAGGTGAAGGTCGGAGTCAA -3 '. The housekeeping gene GAPDH and the small nuclear RNA U6 were used as internal controls for mRNAs and microRNA, respectively. Expression levels of genes were

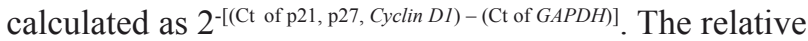

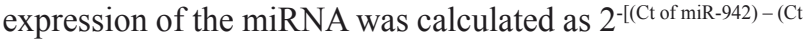
${ }^{\text {of } \mathrm{U} 6)]}$. $\left(\mathrm{C}_{\mathrm{t}}\right.$ represents the threshold cycle for each transcript $)$.

\section{Vectors, retroviral infection and transfection}

The human miR-942 gene was PCR-amplified from genomic DNA and cloned into a pMSCV- puro retroviral vector. pMSCV-miR-942 was cotransfected with the pIK packaging plasmid in HEK293T cells using the standard calcium phosphate transfection method. Thirty-six hours after the cotransfection, supernatants were collected and incubated with cells to be infected for 24 hours in the presence of polybrene $(2.5 \mu \mathrm{g} / \mathrm{ml})$. After infection, puromycin $(0.5 \mu \mathrm{g} / \mathrm{ml})$ was used to select stably transduced cells over a 10-day period [47]. The reporter plasmids containing wild-type (CCTTTGATC; TOP flash) or mutated (CCTTTGGCC; FOP flash) TCF/ LEF DNA binding sites were purchased from Upstate Biotechnology (New York, USA). The 3'UTRs of sFRP4, GSK3 $\beta$, and TLE1, respectively, were amplified and cloned downstream to the luciferase gene in a modified pGL3 control vector. Antagomir-942 was purchased from RIBOBIO Company (Guangzhou, China).

\section{Luciferase reporter assay}

Cells $\left(3 \times 10^{4}\right)$ were seeded in triplicate in 24 well plates. 24-hours later, indicated luciferase reporter plasmids plus $3 \mathrm{ng}$ pRL-TK Renilla plasmid were transfected into the cells using Lipofectamine 2000 Reagent (Life Technologies, USA). 48 hours after transfection, Dual Luciferase Reporter Assay (Promega, USA) was performed according to the manufacturer's instructions.

\section{Western blot analysis}

Western blot analysis was performed using anti- sFRP4 (1:2000, Abcam, Cambridge, MA, USA); anti-GSK3 $\beta$ (1:5000, Abcam, Cambridge, MA, USA), anti-TLE1 (1:3000, Abcam, Cambridge, MA, USA); anti$\beta$-catenin (1:5000, Abcam, Cambridge, MA, USA); anti-cmyc (1:1000, Abcam, Cambridge, MA, USA). To control sample loading, the blotting membranes were stripped and re-probed with an anti- $\alpha$-tubulin or anti-p84 antibody (1:5000, Sigma, Saint Louis, MO, USA). Nuclear extracts were prepared using the Nuclear Extraction Kit (Active Motif), according to the manufacturer's instructions.

\section{miRNP immunoprecipitation}

Cells were co-transfected with HA-Ago 1 together with $100 \mathrm{nM}$ miR-942, followed by HA-Ago1 immunoprecipitation using HA-antibody. Real-time PCR analysis of the IP material was used to test the association of the mRNA of sFRP4, GSK3 $\beta$, and TLE1 with the RISC complex.

\section{Animal studies}

BALB/c-nu mice (4-5 weeks of age, 18-20g) were purchased from the Center of Experimental Animal of Guangzhou University of Chinese Medicine. All experimental procedures were approved by the Institutional Animal Care and Use Committee of affiliated hospital of academy of military medical sciences. The $\mathrm{BALB} / \mathrm{c}$ nude mice were randomly divided into two groups ( $n=6 /$ group) and was inoculated subcutaneously with Eca109/Vector cells $\left(1 \times 10^{6}\right)$ in the left dorsal flank 
and with Eca109/miR-942 cells $\left(1 \times 10^{6}\right)$ in the right dorsal flank per mouse. For in vivo antagomir assay, $1 \times 10^{6}$ Eca109 cells were inoculated subcutaneously in the left dorsal flank of BALB/c nude mice. 7 days later, one hundred microliters of antagomir -942 (diluted in PBS at $2 \mathrm{mg} / \mathrm{ml}$ ) or control antagomir was administrated intratumourally 3 times per week for 2 weeks, starting when the average volume of grown tumours reached approximately $50 \mathrm{~mm}^{3}$. For dosages injection assay, the NOD/SCID mice were randomly divided into 3 groups $(n=$ 6 per group). Indicated cells of 3 dosages $\left(1 \times 10^{4}, 1 \times 10^{3}\right.$, and $1 \times 10^{2}$ ) were inoculated subcutaneously with matrigel (final concentration of $25 \%$ ) into the inguinal folds of NOD/SCID mice. Tumour volume was calculated using the equation (Length*Weight $\left.{ }^{2}\right) / 2$. On day 40, tumours were detected by an IVIS imaging system (Caliper), then animals were euthanized, and the tumours were excised, weighed and paraffin-embedded.

\section{Tumour sphere formation assays}

Five hundred cells were seeded in 6-well ultra-low cluster plates and 10 or 20 cells were seeded in 24-well ultra-low cluster plates for 10 days. Spheres were cultured in DMEM/F12 serum-free medium (Invitrogen, USA) supplemented with 2\% B27 (Invitrogen, USA), $20 \mathrm{ng} /$ $\mathrm{ml} \mathrm{EGF,} 20 \mathrm{ng} / \mathrm{ml} \mathrm{bFGF}$, and $5 \mu \mathrm{g} / \mathrm{ml}$ insulin (PeproTech, USA).

\section{Flow cytometric analysis}

Flow cytometric analysis or flow cytometric cell sorting was conducted using phycoerythrin (PE)conjugated monoclonal mouse anti-human CD90 (Miltenyi Biotec GmbH, Germany). Samples were analyzed and sorted on BD FACS Canto II and FACS Aria I, respectively (BD Biosciences, USA) with data analyzed using FlowJo software (Tree Star Inc, USA).

\section{Chromatin Immunoprecipitation (ChIP)}

Cells $\left(2 \times 10^{6}\right)$ in a $100-\mathrm{mm}$ culture dish were treated with $1 \%$ formaldehyde to cross-link proteins to DNA. The cell lysates were sonicated to shear DNA to sizes of 300-1000 bp. Equal aliquots of chromatin supernatants were incubated with $1 \mu \mathrm{g}$ of anti-c-myc antibody (Abcam, Cambridge, MA) or an anti-IgG antibody (Millipore, Billerica, MA) overnight at $4^{\circ} \mathrm{C}$ with rotation. After reverse cross-link of protein/DNA complexes to free DNA, PCR was performed.

\section{Bioinformatics analysis}

The following on-line software programs were used for bioinformatics analysis: The Cancer Genome Atlas (TCGA) (http://cancergenome.nih.gov/ ); TargetScan 6.2 (http://www. targetscan.org/); and miRanda (http://www. microrna.org/ microrna /getGene Form.do).

\section{Statistical analysis}

All statistical analyses were carried out using SPSS 18.0 statistical software. The Kaplan-Meier method was used to establish survival curves, and the survival differences were compared using the log-rank test. Continuous data were compared using Student's 2-tailed t-test. Multivariate statistical analysis was performed using a Cox regression model. In all cases, $P<0.05$ was considered statistically significant.

\section{Study approval}

For the use of materials for research purposes, prior patient consent was obtained, and study approval was granted by the affiliated hospital of academy of military medical sciences and Cancer Center Institution Board. All animal studies were approved by the Affiliated hospital of Academy of military medical sciences Institutional Animal Care and Use Committee.

\section{ACKNOWLEDGEMENTS}

This study was supported in part by grants from National High Technology Research and Development 863 Program of China (\#2012AA02A201), National Key Technology Research and Development Program of The 12th Five-Year Plan of China (\#2011ZX09102001-29), National Natural Science Foundation of China (\#81260307, \#81060185 and \#81470005), National Clinical Key Specialty Construction Projects of Oncology of National Health and Family Planning Commission of China (Awarding to Tumor Hospital of Yunnan Province: 2013-2014), the Yunnan Province Leading Talent Program of Health System(L-201213), the Yunnan Provincial General Program for Applied Basic Research (\#2011FB209 and \#2012FB069).

\section{CONFLICTS OF INTEREST}

Authors declare that there is no relevant, potential conflicts of interest.

\section{REFERENCES}


cancer, and cancer stem cells. Nature, 2001;414:105-11.

2. Visvader JE, Lindeman GJ. Cancer stem cells in solid tumours: accumulating evidence and unresolved questions. Nat Rev Cancer, 2008;8:755-68.

3. Vermeulen L, Sprick MR, Kemper K, Stassi G, Medema JP. Cancer stem cells--old concepts, new insights. Cell Death Differ, 2008;15:947-58.

4. Vermeulen L, Todaro M, de Sousa Mello F, Sprick MR, Kemper K, Perez Alea M,Richel DJ, Stassi G, Medema JP. Single-cell cloning of colon cancer stem cells reveals a multi-lineage differentiation capacity. Proc Natl Acad Sci U S A, 2008;105:13427-32.

5. O'Brien CA, Kreso A, Jamieson CH. Cancer stem cells and self-renewal. Clin Cancer Res, 2010;16:3113-20.

6. Cui J, Jiang W, Wang S, Wang L, Xie K. Role of Wnt/ $\beta$ catenin signaling in drug resistance of pancreatic cancer. Curr Pharm Des, 2012;18:2464-71.

7. Forghanifard MM, Ardalan Khales S, Javdani-Mallak A, Rad A, Farshchian M,Abbaszadegan MR. Stemness state regulators SALL4 and SOX2 are involved in progression and invasiveness of esophageal squamous cell carcinoma. Med Oncol, 2014;31:922.

8. Zhao Y, Bao Q, Schwarz B, Zhao L, Mysliwietz J, Ellwart J, Renner A, Hirner H, Niess H, Camaj P, Angele M, Gros S, Izbicki J, Jauch KW, Nelson PJ, Bruns CJ.Stem celllike side populations in esophageal cancer: a source of chemotherapy resistance and metastases. Stem Cells Dev, 2014;23:180-92.

9. Nusse R, Fuerer C, Ching W, Harnish K, Logan C, Zeng A, ten Berge D, Kalani Y. Wnt signaling and stem cell control. Cold Spring Harb Symp Quant Biol, 2008;73:59-66.

10. Valenta T, Hausmann G, Basler K. The many faces and functions of $\beta$-catenin.EMBO J, 2012;31:2714-36

11. Hoffmeyer K, Raggioli A, Rudloff S, Anton R, Hierholzer A, Del Valle I, Hein K, Vogt R, Kemler R. Wnt/ $\beta$-catenin signaling regulates telomerase in stem cells and cancer cells. Science, 2012;336:1549-54.

12. Polakis P. Wnt signaling and cancer. Genes Dev, 2000;14:1837-51.

13. Clevers $\mathrm{H}$. Wnt/beta-catenin signaling in development and disease. Cell, 2006; 127:469-80.

14. MacDonald BT, Tamai K, He X. Wnt/beta-catenin signaling: components, mechanisms, and diseases. Dev Cell, 2009;17:9-26.

15. Fodde R, Brabletz T. Wnt/beta-catenin signaling in cancer stemness and malignant behavior. Curr Opin Cell Biol, 2007;19:150-8.

16. Klaus A, Birchmeier W. Wnt signalling and its impact on development and cancer. Nat Rev Cancer, 2008;8:387-98.

17. Reya T, Clevers H. Wnt signalling in stem cells and cancer. Nature, 2005;434:843-50.

18. Bienz M, Clevers H. Linking colorectal cancer to Wnt signaling. Cell, 2000;103:311-20.
19. Tanaka S, Akiyoshi T, Mori M, Wands JR, Sugimachi $\mathrm{K}$. A novel frizzled gene identified in human esophageal carcinoma mediates APC/beta-catenin signals. Proc Natl Acad Sci U S A,1998;95:10164-9.

20. Carmon KS, Loose DS. Secreted frizzled-related protein 4 regulates two Wnt7a signaling pathways and inhibits proliferation in endometrial cancer cells. Mol Cancer Res, 2008;6:1017-28.

21. Gibb N, Lavery DL, Hoppler S. sfrp1 promotes cardiomyocyte differentiation in Xenopus via negativefeedback regulation of Wnt signalling. Development, 2013;140:1537-49.

22. Bergmann K, Sypniewska G. Secreted frizzled-related protein 4 (SFRP4) and fractalkine (CX3CL1) - Potential new biomarkers for $\beta$-cell dysfunction and diabetes. Clin Biochem, 2014;47:529-32.

23. Clevers $H$, Nusse R. Wnt/ $\beta$-catenin signaling and disease. Cell, 2012;149:1192-205.

24. Daniels DL, Weis WI. Beta-catenin directly displaces Groucho/TLE repressors from Tcf/Lef in Wnt-mediated transcription activation. Nat Struct Mol Biol, 2005;12:36471.

25. Ekici AB, Hilfinger D, Jatzwauk M, Thiel CT, Wenzel D, Lorenz I, Boltshauser E, Goecke TW, Staatz G, MorrisRosendahl DJ, Sticht H, Hehr U, Reis A, Rauch A.Disturbed Wnt Signalling due to a Mutation in CCDC88C Causes an Autosomal Recessive Non-Syndromic Hydrocephalus with Medial Diverticulum. Mol Syndromol, 2010;1:99-112.

26. Chodaparambil JV, Pate KT, Hepler MR, Tsai BP, Muthurajan UM, Luger K, Waterman ML, Weis WI. Molecular functions of the TLE tetramerization domain in Wnt target gene repression. EMBO J, 2014;33:719-31.

27. Malanchi I, Peinado H, Kassen D, Hussenet T, Metzger D, Chambon P, Huber M,Hohl D, Cano A, Birchmeier W, Huelsken J. Cutaneous cancer stem cell maintenance is dependent on beta-catenin signalling.Nature, 2008;452:6503.

28. Esophageal cancer: epidemiology, pathogenesis and prevention. Nat Clin Pract Gastroenterol Hepatol, 2008;5:517-26.

29. Schweigert M, Dubecz A, Stein HJ. Oesophageal cancer--an overview. Nat Rev Gastroenterol Hepatol, 2013;10:230-44.

30. Huang D, Gao Q, Guo L, Zhang C, Jiang W, Li H, Wang J, Han X, Shi Y, Lu SH. Isolation and identification of cancer stem-like cells in esophageal carcinoma cell lines. Stem Cells Dev, 2009;18:465-73.

31. Burk RD. Treatment of renal-cell cancer by transplantation of allogeneic stem cells.N Engl J Med, 2001;344:137; author reply 138 .

32. Sharkis SJ, Jones RJ, Civin C, Jang YY. Pluripotent stem cell-based cancer therapy: promise and challenges. Sci Transl Med, 2012;4:127ps9.

33. Katoh M, Katoh M. WNT signaling pathway and stem cell signaling network. Clin Cancer Res, 2007;13:4042-5. 
34. van Amerongen R, Bowman AN, Nusse R. Developmental stage and time dictate the fate of Wnt/beta-cateninresponsive stem cells in the mammary gland. Cell Stem Cell, 2012;11:387-400.

35. Cadigan KM, Nusse R. Wnt signaling: a common theme in animal development. Genes Dev, 1997;11:3286-305.

36. Robinson JA, Chatterjee-Kishore M, Yaworsky PJ, Cullen DM, Zhao W, Li C, Kharode Y, Sauter L, Babij P, Brown EL, Hill AA, Akhter MP, Johnson ML, Recker RR, Komm BS, Bex FJ. Wnt/beta-catenin signaling is a normal physiological response to mechanical loading in bone. $\mathrm{J}$ Biol Chem, 2006;281:31720-8.

37. Marson A, Foreman R, Chevalier B, Bilodeau S, Kahn M, Young RA, Jaenisch R. Wnt signaling promotes reprogramming of somatic cells to pluripotency. Cell Stem Cell, 2008;3:132-5.

38. Kawano Y, Kypta R. Secreted antagonists of the Wnt signalling pathway. J Cell Sci, 2003;116:2627-34.

39. Suzuki H, Watkins DN, Jair KW, Schuebel KE, Markowitz SD, Chen WD, Pretlow TP,Yang B, Akiyama Y, Van Engeland M, Toyota M, Tokino T, Hinoda Y, Imai K, HermanJG, Baylin SB. Epigenetic inactivation of SFRP genes allows constitutive WNT signaling in colorectal cancer. Nat Genet, 2004;36:417-22.

40. Warrier S, Balu SK, Kumar AP, Millward M, Dharmarajan A. Wnt antagonist, secreted frizzled-related protein 4 (sFRP4), increases chemotherapeutic response of glioma stem-like cells. Oncol Res, 2013;21:93-102.

41. Belshaw NJ, Elliott GO, Foxall RJ, Dainty JR, Pal N, Coupe A, Garg D, Bradburn DM, Mathers JC, Johnson IT. Profiling $\mathrm{CpG}$ island field methylation in both morphologically normal and neoplastic human colonic mucosa. Br J Cancer, 2008;99:136-42.

42. Lee AY, He B, You L, Dadfarmay S, Xu Z, Mazieres J, Mikami I, McCormick F, Jablons DM. Expression of the secreted frizzled-related protein gene family is downregulated in human mesothelioma. Oncogene, 2004;23:6672-6.

43. Brebi P, Hoffstetter R, Andana A, Ili CG, Saavedra K, Viscarra T, Retamal J, Sanchez R, Roa JC. Evaluation of ZAR1 and SFRP4 methylation status as potentials biomarkers for diagnosis in cervical cancer: exploratory study phase I. Biomarkers, 2014;19:181-8.

44. Valencia A, Román-Gómez J, Cervera J, Such E, Barragán E, Bolufer P, Moscardó F, Sanz GF, Sanz MA. Wnt signaling pathway is epigenetically regulated by methylation of Wnt antagonists in acute myeloid leukemia. Leukemia, 2009;23: 1658-66.

45. Zinovyeva MV, Monastyrskaya GS, Kopantzev EP, Vinogradova TV, Kostina MB, Sass AV, Filyukova OB, Uspenskaya NY, Sukhikh GT, Sverdlov ED. Identification of some human genes oppositely regulated during esophageal squamous cellcarcinoma formation and human embryonic esophagus development. Dis Esophagus,
2010;23:260-70.

46. Andl CD, Mizushima T, Nakagawa H, Oyama K, Harada H, Chruma K, Herlyn M, Rustgi AK. Epidermal growth factor receptor mediates increased cell proliferation, migration, and aggregation in esophageal keratinocytes in vitro and in vivo. J Biol Chem, 2003; 278:1824-30.

47. Hahn WC, Dessain SK, Brooks MW, King JE, Elenbaas B, Sabatini DM,DeCaprio JA,Weinberg RA. Enumeration of the simian virus 40 early region elements necessary for human cell transformation. Mol Cell Biol, 2002 ;22:211123. 